\title{
Structural Performance of Isolated Steel Beam-to-Column Connection
}

\author{
Iman Faridmehr ${ }^{1, *}$, Mahmood Md. Tahir ${ }^{1}$, Mohd Hanim Osman², Abbas Razavykia ${ }^{3}$ \\ ${ }^{1}$ UTM Construction Research Centre (CRC), Institute of Smart Infrastructures and Innovative Construction, \\ Universiti Teknologi Malaysia (UTM), Skudai, Johor Bahru, 81300, Malaysia \\ ${ }^{2}$ Forensic Engineering Centre (FEC), Universiti Teknologi Malaysia (UTM), Skudai, Johor Bahru, 81300, Malaysia \\ ${ }^{3}$ Department of Mechanical and Aerospace Engineering, Politecnico di Torino, Corso Duca degli Abruzzi 24, 10129 Torino, Italy \\ *Corresponding author: s.k.k-co@live.com
}

\begin{abstract}
The present study attempts to determine the main characteristics of a new proposed steel connection retrofitted by an elastomeric isolator. Its stiffness, strength, and ductility are investigated. The elastomeric isolators were designed according to the Japanese Society of Base Isolation with the aim of improving the energy dissipation of the connection. Experimental tests were conducted to evaluate the moment rotation $(M-\theta)$ curve of the proposed connection as well as of fully-rigid (SidePlate) and semi-rigid (flush end-plate) connections. The behaviour of beams with flexible and fixed-end connections was also studied by classical methods of analysis. The initial stiffness and classification index of the connections were identified by an analytical calculation in compliance with the methods suggested by Eurocode 3 Part 1-8 and ANSI/AISC 360-10. The results confirmed that the new proposed connection can be classified as a flexible connection in terms of its initial stiffness; however, it developed $90 \%$ of the plastic moment capacity of a connected beam. Besides, it showed that the isolated connection did address the AISC drift angle capacity requirement of $\theta_{S D}$ for a special moment frame (SMF).
\end{abstract}

Keywords: classification index, beam to column connection, semi-rigid, moment-rotation curve

Cite This Article: Iman Faridmehr, Mahmood Md. Tahir, Mohd Hanim Osman, and Abbas Razavykia, "Structural Performance of Isolated Steel Beam-to-Column Connection." American Journal of Civil Engineering and Architecture, vol. 6, no. 2 (2018): 68-69. doi: 10.12691/ajcea-6-2-4.

\section{Introduction}

Subsequent to the Northridge disasters, the reliability of welded moment- resisting connections was found to be strongly compromised due to the widespread brittle damage identified in many frames [1,2]. According to these observations, great efforts in experimental and theoretical research were developed in the USA, Japan and Europe on the seismic behaviour of both welded and other configurations of steel beam-to-column connections. As found by several researchers, including $[3,4,5]$, the dynamic performance of semi-rigid structures can be improved due to the longer period and increase in damping because of the connection's high level of dissipative friction. These effects can be considered as a kind of self-isolation that leads to a substantial decrease of the seismic actions of the structures. The SAC Steel Project [6], begun after the Northridge earthquake to investigate steel beam-to-column connections casualties, introduced bolted connections as an alternative to the standard welded connections [6,7].

Currently, the qualification of all resisting moment connections is undertaken through experimental simulations applying the loading protocol according to the AISC seismic provisions [8]. This test endeavours to show the ability of the connection to resist a large plastic drift angle with organized ductile yielding in the particular location of the connected beam. A number of research programs have been conducted by the Federal Emergency Management Agency (FEMA) $[9,10]$ to characterize the performance of a steel connection subjected to cyclic loading for seismic design purposes. For example, the evaluation of the cyclic performance of the Post-Northridge (PN) steel connections was carried out using both experimental tests and FE modelling simulations [11-15].

The present paper considers a new proposed beam-tocolumn connection retrofitted by two elastomeric isolators as shown in Figure 1. The configuration of the connection allows the connected beams to develop the full plastic rotation angle without any interference to the column shear panel zone. The proposed connection involves a retrofitting by elastomeric isolators which are installed between the cover plates and the beam flanges. The reason for mounting isolators in the proposed connection is to dissipate more energy without a stress concentration or failure in the main connection's components. Moreover, it is predicted that mounting isolators leads to bigger hysteresis loops after interstorey drift angles of 0.04 radians in which the superstructure remains in immediate occupancy after a severe earthquake. Finally, by installing two strong sideplates, there will be no stresses to the column shear panel zone, resulting in a $100 \%$-rigid panel zone. 


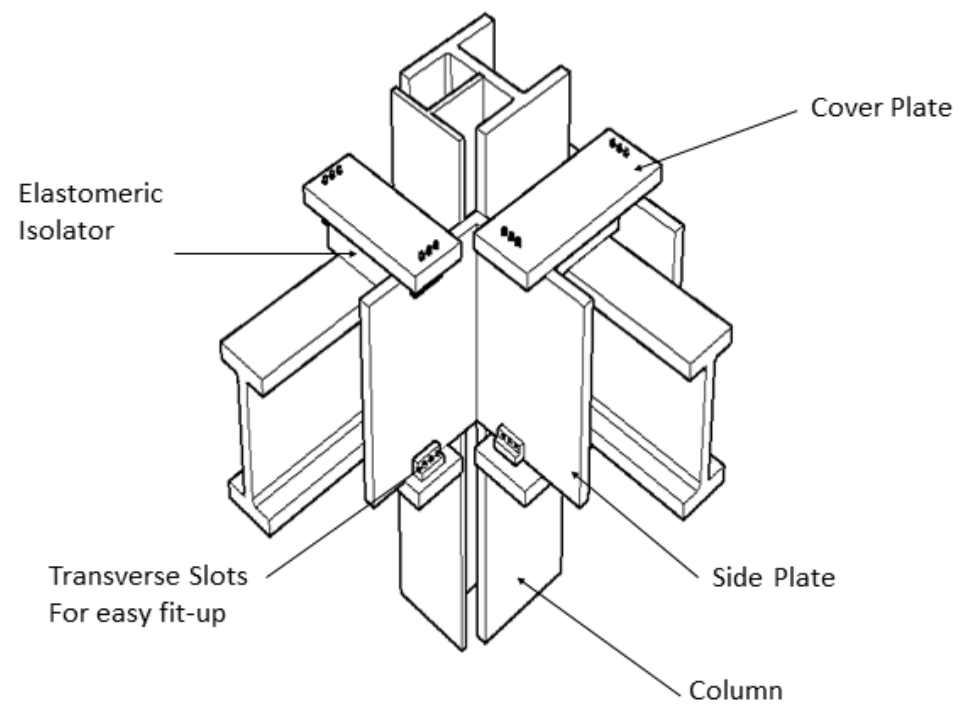

Figure 1. New proposed connection

\section{Connection Classification Index by Eurocode 3 and AISC Specification}

Steel frames have been traditionally designed by supposing that the connections are perfectly fully-rigid or flexible. It is assumed that a perfectly flexible connection means that transferring moment between the beam and column is not possible; in other words, the connection does not have rotational stiffness although it transmits shear and axial forces to the connected columns (Figure 2(a)). Instead, fully-rigid connections have significant rotational stiffness, and consequently transfer all sorts of loads among the beam and the attached column (Figure 2(b)). In reality, beam-to-column connections have a determinate rotational stiffness and are, for that reason, semi-rigid (Figure 2(c)).

In the past decades, analysis techniques of semi-rigid connections have developed significantly, to identify a realistic connection performance, beginning with the slope-deflection method in the 1930s [16] and moment redistribution approaches, with the matrix stiffness approach in the 1960s [17], and currently using iterative analysis approaches [18]. The exact performance of a connection may be integrated in the overall analysis through the moment-rotation $(M-\varphi)$ curve (Figure 3$)$. This is accomplished by determining the mechanical characteristics of the connection, such as its moment resistance $\left(M_{n}\right)$, rotational stiffness $\left(S_{j . i n i}\right)$, and rotational capacity $\left(\varphi_{u}\right)$.
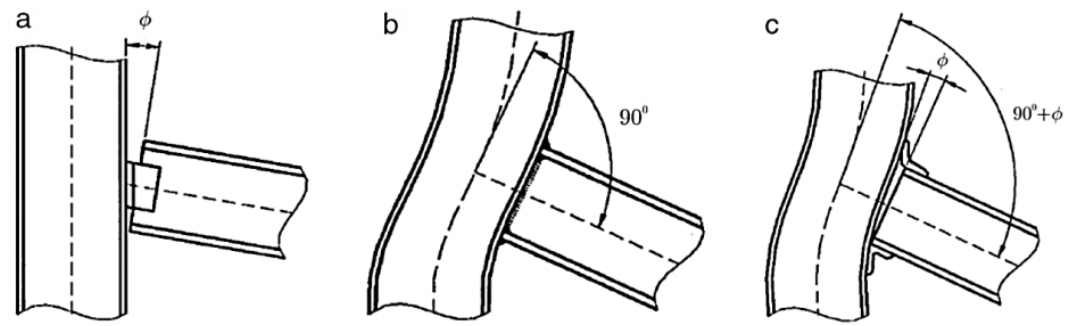

Figure 2. Beam-to-column connection performance: (a) ideally flexible, (b) fully-rigid, (c) semi-rigid

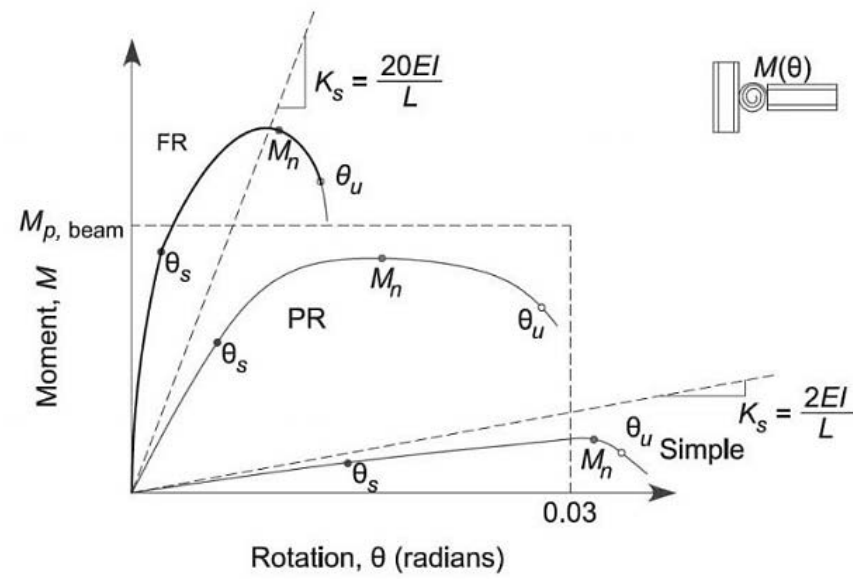

Figure 3. Moment-rotation curve of fully-rigid (FR), semi-rigid (PR) and flexible connections [19] 
According to AISC [19], connections are classified based on their strength, stiffness and ductility. The secant stiffness, $K_{S}$, is defined by

$$
K_{s}=M_{s} / \theta_{s}
$$

where

$M_{S}=$ moment at service loads, $(\mathrm{kN}-\mathrm{m})$

$\theta_{S}=$ rotation at service loads, rad.

If $\frac{k_{s} L}{E I} \geq 20$, the connection is classified as fully-rigid (FR) (it can maintain the rotation among members). If $\frac{k_{s} L}{E I} \leq 2$, the connection is known as flexible (it experiences rotation without increasing moment). The stiffnesses that lie between these two limits are classified as semi-rigid connections, and their stiffness, strength and ductility have to be modelled in the analysis process.

The maximum moment resistance of the connection is defined to be $M_{n}$, shown in Figure 3. For an $(M-\theta)$ curve without a peak moment, the moment at a rotation of 0.02 rad is identified as the maximum strength of the connection [20]. Connections that transfer less than $20 \%$ of the $M_{p}$ (plastic moment of the connected beam) at a rotation of $0.02 \mathrm{rad}$ are considered to have no flexural strength. Furthermore, the rotation capacity, $\theta_{u}$, is defined as the exact point where the moment resistance has reduced to $0.8 M_{n}$ or the connection has experienced a rotation of more than 0.03 rad. This second value is used in the situation with no clear decrease in strength up to where significant deformation occurs. A comparison has to be made between the maximum rotation capacity, $\theta_{u}$, and the required rotation strength. A value of $0.03 \mathrm{rad}$ is considered the minimum connection rotation resistance according to the Seismic Provisions for Special Moment Frames specification [19].

According to Eurocode 3 Part 1-8 [21], a connection is classified as fully-rigid, flexible or semi-rigid through evaluating its initial rotation stiffness, $S_{j . i n i}$, and the limits shown in Figure 4(a), where zone 1 symbolizes a fully-

$$
S_{j, \text { ini }} \geq \frac{K_{b} E I_{b}}{L_{b}},
$$

where

$K_{b}$ is taken as 8 for braced frames

$K_{b}$ is taken as 25 for moment frames.

A flexible connection transfers shear and axial forces, without developing considerable moments. Based on Figure 4(a), connections are categorized as flexible (zone 3) if

$$
S_{j, \text { ini }} \leq \frac{0.5 E I_{b}}{L_{b}} .
$$

The beam-to-column connections that are not categorized as either fully-rigid or flexible are classified as semi-rigid (zone 2). Semi-rigid connections provide an expected rotation between the connected beam, based on the moment-rotation $(M-\theta)$ curve characteristic of the connections. Semi-rigid connections transfer bending moments as well as shear forces. The bilinear concept was assumed for determining the initial stiffness, $S_{j . i n i}$, to form the moment-rotation curve. In this technique the intercept constant moment, $M_{i}$, is selected as the moment equivalent to the intersection of the moment axis and the strain hardening tangent stiffness line, which passes through the last point, as shown in Figure 4(b). As a result, the intercept constant moment is highly dependent on the connection's ultimate moment [22].

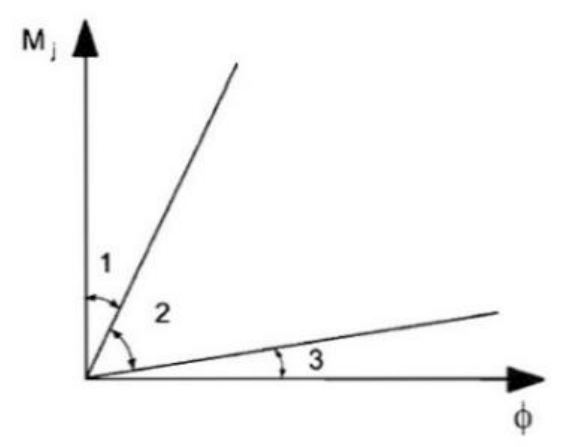

(a)

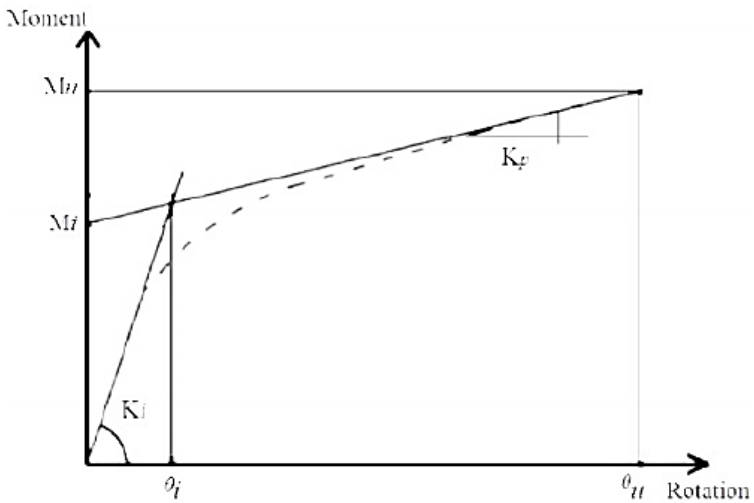

(b)

Figure 4. Classification of joints according to Eurocode 3 (a) and description of initial stiffness (b)

According to EC3, a connection is classified as fully-rigid, flexible or semi-rigid by comparing its maximum moment capacity, $M_{n}$, with the design moment resistances of the connected beam. A connection is categorised as fully-rigid if

$$
M_{n} \geq M_{p},
$$

where

$M_{p}$ is the connected beam plastic moment.

Connections with design moment capacity, $M_{n}$, less than 0.25 times the connected beam's plastic moment $\left(M_{p}\right)$ are categorized as flexible connections.

\section{Isolator Design Procedure}

Base isolation is recognized as a satisfactory seismic protection strategy that significantly separates a structure from its substructure, which adequately protects the structure against seismic forces. Connection isolation is aimed at dissipating the energy of the earthquake by placing isolator devices at selected connections. Among the best recognised connection isolation systems are the friction type and the viscoelastic type. The viscoelastictype isolation system is the most commonly used. These are usually made of alternating layers of elastomeric 
material and steel. A number of structures with added isolation systems have been investigated [23,24]. The incorporation of an isolation system into a structure, especially for a tall building, is beneficial and significantly improves the seismic performance.

The design of seismic isolation systems begins with a consideration of the maximum applied loads and continues with determining the overall thickness and cross-sectional area of the isolator, and finally a calculation of the thicknesses of the rubber layer $\left(t_{r}\right)$ and the steel laminates $\left(t_{s}\right)$. A flowchart has been prepared by the present authors to design isolators based on the Uniform Building Code (UBC) [25] of the Japan Society of Base Isolation [26]. It is presented in Figure 5.

\section{Test Rig and Case Studies}

For full-scale experimental testing, a test rig with a 1.3-metre-span cantilever beam and a 1-metre high column was employed. The reacting frame was constructed by using wide channel sections with 22-mm holes that were anchored to the strong floor of the laboratory (Figure 6). The columns were restrained from lateral movement at both ends. The beam was also restrained from lateral movement at the middle. The concentrated load was applied by a hydraulic jack at the tip of the beam. For simulating quasi-static loading, a monotonically push-down loading was employed, where the loading was accomplished using $5 \mathrm{kN}$ increases until the event of a substantial deflection in the beam. After that, the increment of vertical displacement of the beam controlled the loading sequence, as a small load increment leads to a significant increase in deflection. This process continued until the total collapse of the specimen. A failure was recognized once a sudden or significant decrease in the applied load was observed or a significant deformation occurred. An inclinometer was attached at the connection shear panel zone to measure the rotational deformation. Moreover, the vertical deflection of the specimen was measured by using a linear LVDT installed at the tip of the beam.

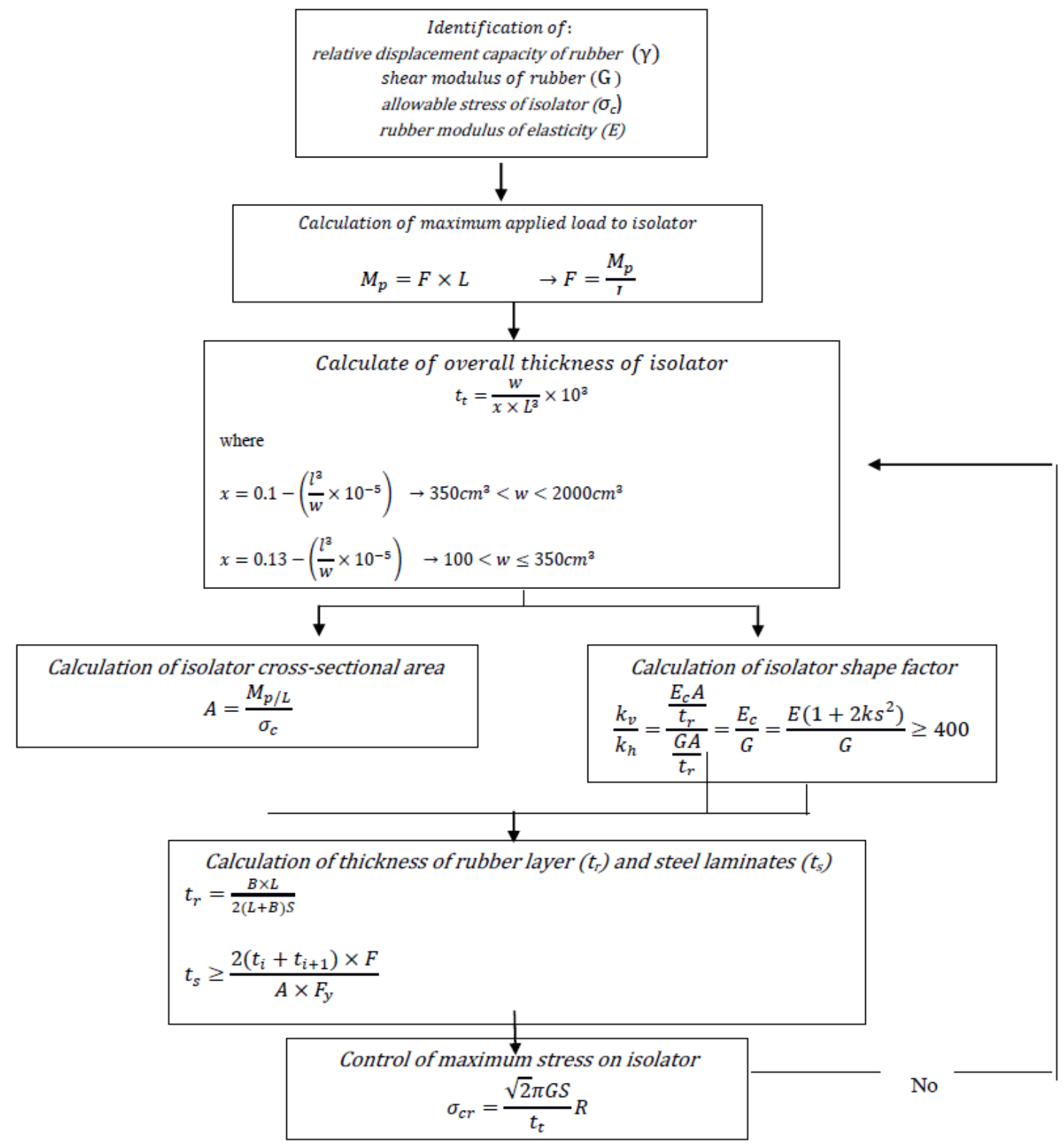

Figure 5. Design flowchart for an elastomeric isolation system 

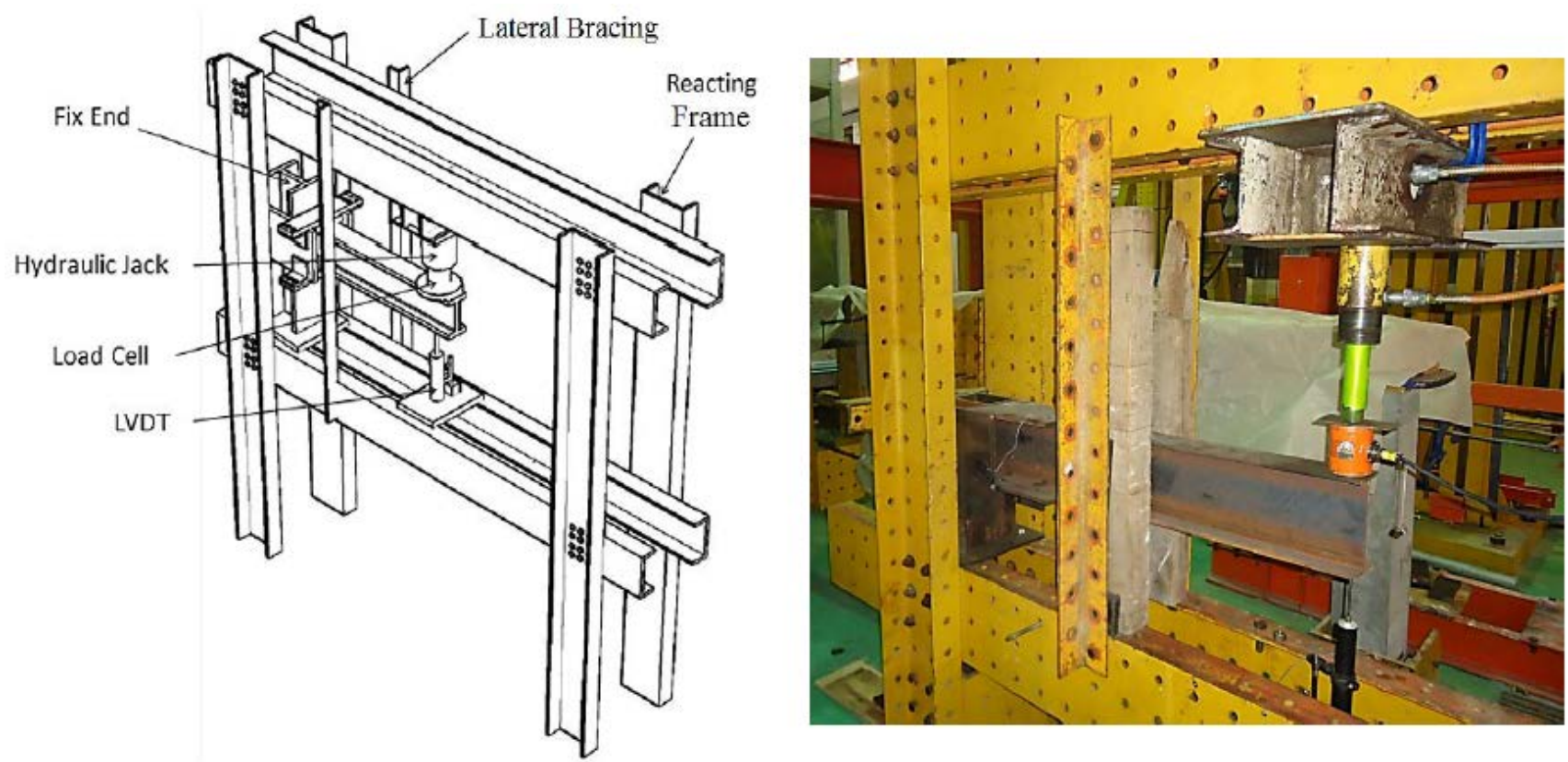

Figure 6. Test rig for experimental test

\subsection{Description of Specimens}

Three full-scale specimens, a flush end-plate (FEP), a SidePlate, and the new proposed beam-to-column connection, were prepared for testing at the structural laboratory of the Universiti Teknologi Malaysia. In this study the flush end-plate (FEP) connection components were selected according to the norm and practice of existing steel structures in Malaysia, which it is believed were not designed to develop the full capacity of the connected beam. Besides, as a country located in low seismic zone that has not experienced severe earthquakes so far, the connection was designed only to resist gravity loading and continuity plates were omitted.

In the Side Plate connection, a pair of parallel full-depth side plates were incorporated to join the beam to the column. The SidePlate moment connection was designed in such a way that the deformation and energy dissipation mechanisms appear outside the connection components and the column itself. The connection between the beam and column is carried out through two cover plates attached to the beam end and the side-plates. Therefore, the beam will never touch the column, so that this physical separation eliminates any peaked tri-axial stress concentration present in the entire welded moment connection types. Moreover, the application of two thick side-plates operating with column webs will eliminate the unbalanced shear distortion within the panel zones. The SidePlate moment connection is prequalified for use in special moment frame (SMF) and intermediate moment frame (IMF) systems within the limitations of ANSI/AISC 358 [8].

The new proposed connection system is constructed exclusively of fillet welds for shop fabrication and nuts and bolts for field erection. The connection features a physical separation, or gap, between the face of the column flange and the end of the beam. The connection of the beam to the column is accomplished with parallel fulldepth side-plates that sandwich and connect the beam and the column. Two isolators are attached to the top and bottom beam flanges in order to dissipate seismic energy without significant failure to the connection component, connected beam, or column. The isolator's top coverplates (rectangular shaped) also serve to bridge any difference between the flange widths of the beam and of the column. The connection of the beam to the side-plate is accomplished through angles which are bolted to the isolation's top cover-plates. The proposed connection is proportioned to develop the probable maximum moment capacity of the connected beam. Beam flexural, axial and shear forces are transferred to the top and bottom rectangular isolator's cover-plates via the bolt bearing. The side-plates transfer all of the forces from the beam across the physical gap to the column via the shop fillet welding (a total of four shop fillet welds; two for each column flange). Plastic hinge formation is intended to occur primarily in the beam away from the column face, with limited yielding occurring in some of the connection elements. Figure 7 and Table 1 show the geometrical configuration and section properties of all three beam-tocolumn connections.

Table 1. Connections properties

\begin{tabular}{|c|c|c|c|c|c|}
\hline $\begin{array}{l}\text { Connection } \\
\text { Type }\end{array}$ & Column Section & Beam Section & $\begin{array}{l}\text { Thickness of End-Plate / } \\
\text { Side- Plate (mm) }\end{array}$ & $\begin{array}{l}\text { Thickness of Cover- } \\
\text { Plate (mm) }\end{array}$ & $\begin{array}{c}\text { Size of } \\
\text { Bolts (mm) }\end{array}$ \\
\hline SidePlate & HB $200 \times 200 \times 56.2$ & HB $200 \times 100 \times 20.9$ & 10 & 10 & - \\
\hline Flush end-plate & HB $200 \times 200 \times 56.2$ & HB $200 \times 100 \times 20.9$ & 12 & - & M20 \\
\hline New Proposed & HB $200 \times 200 \times 56.2$ & HB $200 \times 100 \times 20.9$ & 10 & 12 & M16 \\
\hline
\end{tabular}



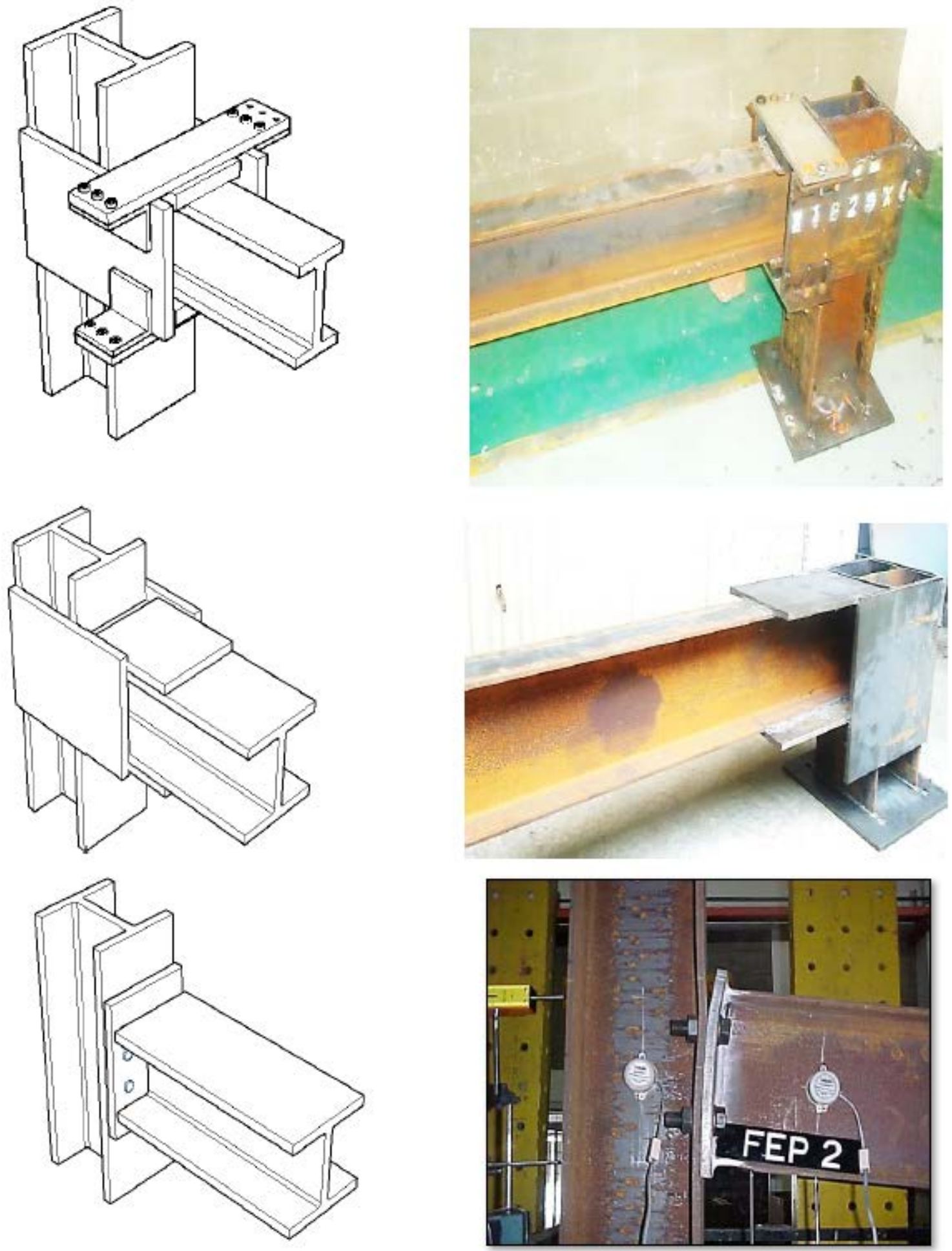

Figure 7. Geometrical configuration of specimens (new proposed, SidePlate and flush end-plate)

Top Steel Mounting Plate(10mm)

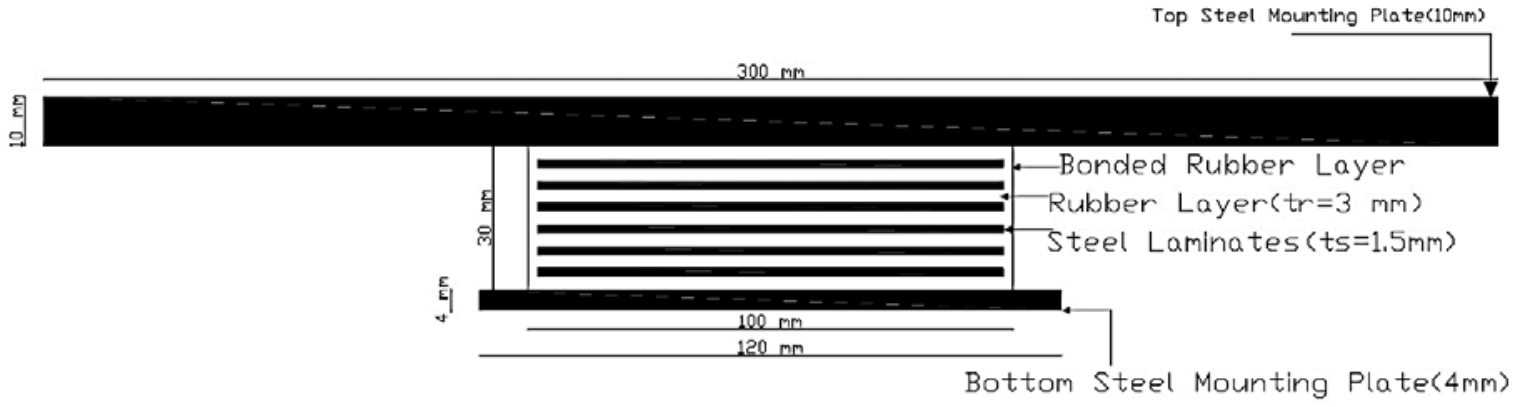

Figure 8. Cross-section of elastomeric isolator 
Figure 8 shows the cross-section of the isolator which consists of a rubber layer and steel laminates. Note that the number and thickness of the steel laminates severely control the initial stiffness of the connection. The top steel mounting plate should also have adequate bending capacity to develop the full plastic moment capacity of the connected beam.

Hot-rolled I-shaped sections in conformity with the British Standards Institute BS EN 10113 [27] were used in this study. In this research two sections were used for the column and beam in which the strong column-weak beam theory according to the AISC regulation was considered. Table 2 illustrates the properties of the sections.

A number of tensile tests were performed on the flanges and webs of the columns, beams, and end-plates of the specimens, and are highlighted in Table 3. In this table, fy is defined as the yield strength, $f u$ is the ultimate strength, and $E$ is the modulus of elasticity.

Table 2. Section properties

\begin{tabular}{|c|c|c|c|c|c|c|}
\hline Section & Depth (mm) & Width $(\mathrm{mm})$ & Flange Thickness $(\mathrm{mm})$ & Web Thickness $(\mathrm{mm})$ & $I_{x x} \square 10^{8}(\mathrm{~mm})^{4}$ & $M_{p}(\mathrm{kN} . \mathrm{m})$ \\
\hline HB $200 \times 200 \times 56.2$ & 200 & 204 & 12 & 12 & 0.4982 & 125 \\
\hline HB 200 x $100 \times 20.9$ & 200 & 100 & 8 & 5.5 & 0.1806 & 72 \\
\hline
\end{tabular}

Table 3. Material properties

\begin{tabular}{|c|c|c|c|c|}
\hline $\begin{array}{c}\text { Modulus of Elasticity, E } \\
\left(\mathrm{kN} / \mathrm{mm}^{2}\right)\end{array}$ & $\begin{array}{l}\text { Ultimate Strength, } f u \\
\left(\mathrm{~N} / \mathrm{mm}^{2}\right)\end{array}$ & $\begin{array}{l}\text { Yield Strength, fy } \\
\left(\mathrm{N} / \mathrm{mm}^{2}\right)\end{array}$ & Beams and Columns & No. \\
\hline 194 & 528 & 367 & 200 x 200 x 56.2 (flange) & \multirow{2}{*}{1} \\
\hline 198 & 547 & 385 & $200 \times 200$ x 56.2 (web) & \\
\hline 193 & 510 & 351 & $200 \times 100$ x 20.9 (flange) & \\
\hline \multirow[t]{2}{*}{192} & 540 & 351 & 200 x 100 x 20.9 (web) & 2 \\
\hline & & & Plate (10 mm) & \multirow{4}{*}{3} \\
\hline 203 & 467 & 305 & P1 & \\
\hline 205 & 491 & 308 & $\mathbf{P} 2$ & \\
\hline \multirow[t]{2}{*}{204} & 470 & 309 & P3 & \\
\hline & & & Plate (12 mm) & \multirow{4}{*}{4} \\
\hline 204 & 515 & 310 & $\mathrm{P} 1$ & \\
\hline 205 & 524 & 311 & $\mathrm{P} 2$ & \\
\hline 203 & 507 & 308 & P3 & \\
\hline
\end{tabular}

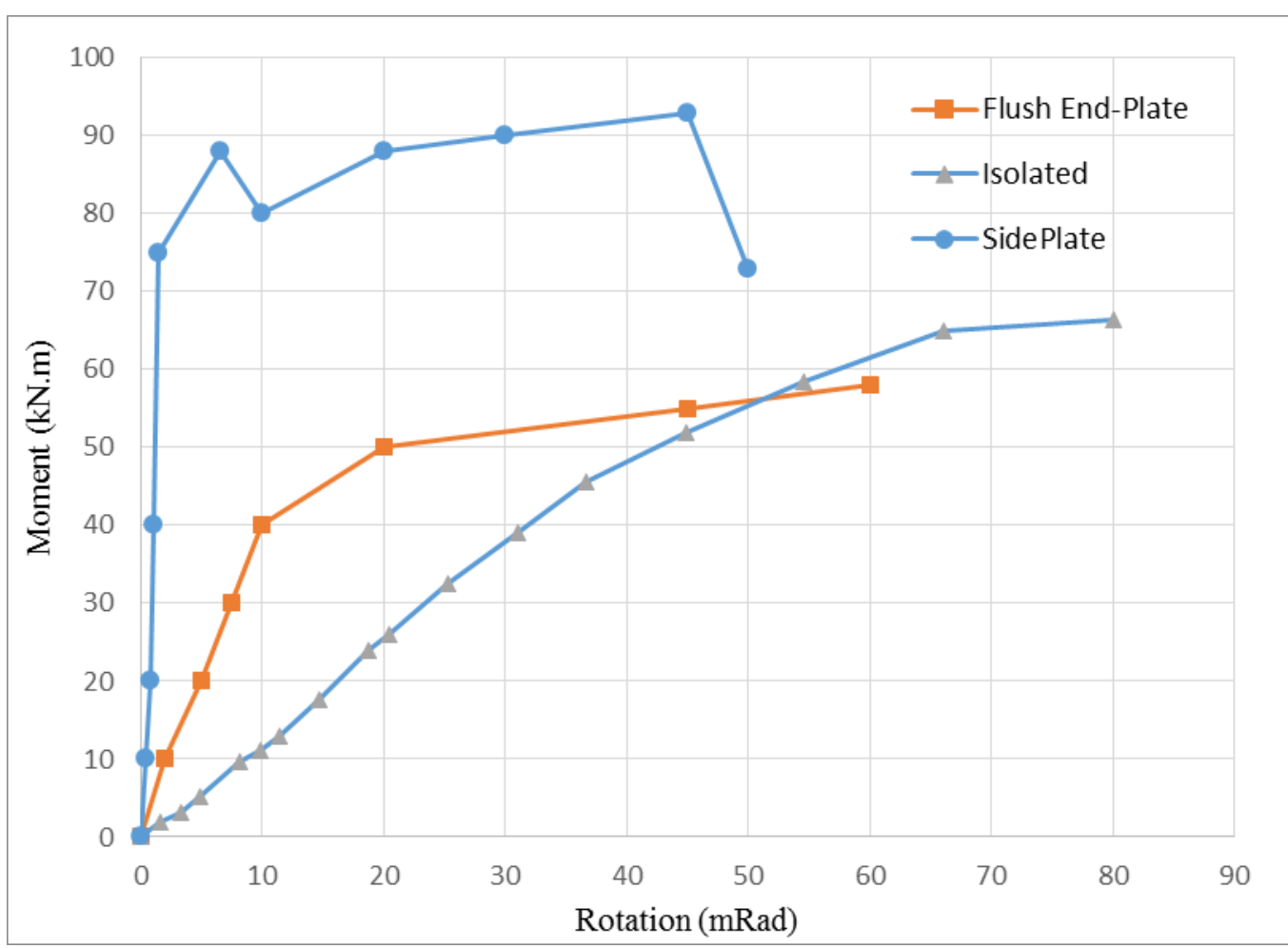

Figure 9. Moment-rotation curves of all three specimens 


\section{Results and Discussion}

The moment-rotation curves for all three specimens are shown in Figure 9.

The flush end-plate experienced a linear behaviour in the first phase and then continued with a non-linear performance, slowly losing its stiffness with increasing applied load. This is recognised as due to the concentrated tensile force applied to the tension region of the end-plate over the top bolt rows. The push-down loading was stopped due to a large rotation as the moment resistance began to decrease. A loss of stiffness and total collapse of the specimen was recognised as: i) buckling of the column flange, ii) yielding and deformation of the end-plate, and iii) yielding of the column web. Throughout the push-down loading, no slip was seen among the column face and end-plate, as the tightness of the bolts was set accurately during fabrication. In the SidePlate specimen, in a first phase of losing stiffness, a plastic hinge appeared at the beam's top flange at $70 \mathrm{kN}$ push-down loading. At this step, the beam flanges experienced a slight but visible buckling. The formation of plastic hinges was identified at a yielding level above $1900 \mu$ (micro-strain) recorded by a strain gauge. Then, in the next phases of the push-down loading, the beam's top flange exhibited the complete formation of the anticipated plastic mechanism. However, the observation of significant global hardening was noticeable. This confirms the ability of the SidePlate to develop the full capacity of the connected beams. Furthermore, once the vertical loading was in the range of $90 \mathrm{kN}$, the strain gauge was absolutely away from the yield level and showed a strain of $5000 \mu$ (3 times beyond the yield level). At a push-down loading of $93 \mathrm{kN}$ and drift angle of 0.02 rad, the beam flanges experienced a series of fractures, causing the severe failure of the SidePlate. Unlike the SidePlate and flush end-plate, the new proposed connection experienced exclusively linear behaviour up to $0.065 \mathrm{rad}$, in which the elastomeric isolators absorbed the whole applied load with no interference with the other connection components. The connection resisted a moment of $66 \mathrm{kN}$.m prior to a yielding in the top cover-plate. The yielding of the top cover-plate along with further failure propagation of the elastomeric isolators was the governing failure mode according to the experimental assessment as shown in Figure 10.

\subsection{ANSI/AISC 360-10 Classification Index}

Table 4 shows the calculated amounts of $\frac{k_{s} L}{E I}$ for all three beam-to-column connections, which indicate that the flush end-plate and isolated connections can be categorized as flexible connections, as the AISC used the value of 2 as the boundary limitation. Besides, it was noticed that the flush end-plate and isolated connections could not develop the plastic moment of the connected beams, in which the ratio of the connection moment resistance, $M_{n}$, to the beam plastic moment, $M_{p}$ beam, was 0.8 and 0.91 , respectively. Even though these two types of connections were categorized as flexible connections (based on their stiffness), the experimental test showed that widespread deformations appeared in the column flange and inside the tension region of the end-plate for the flush end-plate connection, and in the cover-plate for the isolated connection. Therefore, the connection flexibility has to be considered in the analysis process, and therefore the bending moment diagrams and internal forces made under the theory of fully-rigid connection are associated with extensive error. Table 4 also shows that the SidePlate should be categorised as a semi-rigid connection as it could not achieve the fully-rigid limitation value of 20 for $\frac{k_{s} L}{E I}$. However, the ratio of $M_{n}$ to $M_{p \text {, beam }}$ was 1.29 in this connection, indicating the ability of this connection to develop the full capacity of the connected beam.

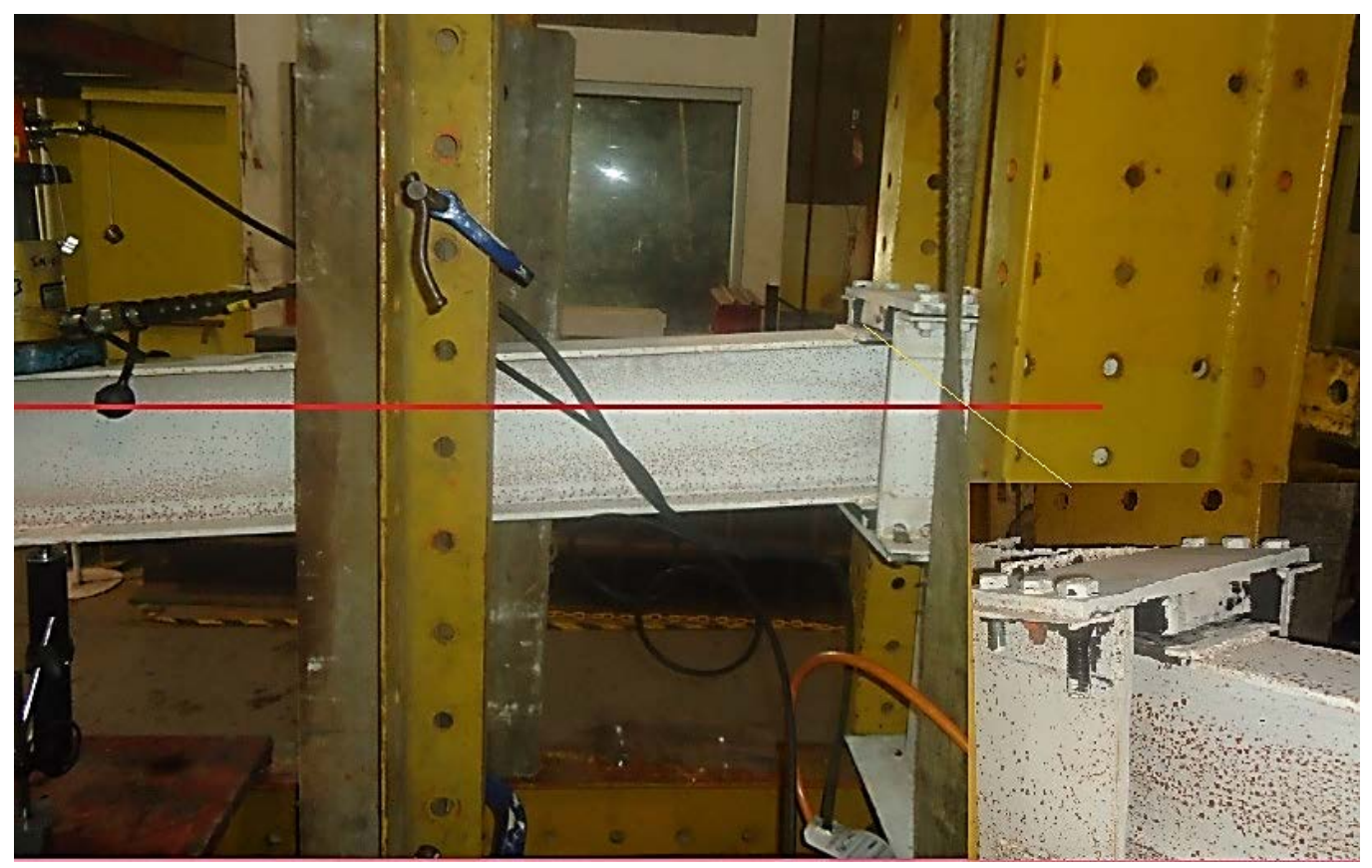

Figure 10. Damage state of the isolated connection 
Table 4. Connection assessment based on AISC classification

\begin{tabular}{|c|c|c|c|c|c|c|c|}
\hline$\frac{k_{s} L}{E I}$ & $\left(\frac{k N \cdot m}{\text { radian }} \times 10^{3}\right)$ & $\begin{array}{c}\text { Mp, Beam } \\
(k N . m)\end{array}$ & $\begin{array}{c}\theta \mathrm{u} \\
(\text { radian })\end{array}$ & $\begin{array}{c}\theta \mathrm{s} \\
(\text { radian })\end{array}$ & $\begin{array}{c}\mathrm{Mn} \\
(k N . m)\end{array}$ & $\begin{array}{c}\text { Ms } \\
(k N . m)\end{array}$ & Specimen \\
\hline 1.56 & 4.2 & 72 & 0.06 & 0.01 & 58 & 42 & Flush End-Plate \\
\hline 15.5 & 42 & 72 & 0.045 & 0.001 & 93 & 42 & SidePlate \\
\hline 0.5 & 1.3 & 72 & 0.08 & 0.031 & 66 & 42 & Isolated \\
\hline
\end{tabular}

According to the AISC classification, connections that convey less than $20 \%$ of the beam plastic moment at rotations of 0.02 rad have to be considered as flexible. Figure 9 shows that all three beam-to-column connections transferred more than $20 \%$ of the beam's plastic moment at rotations of 0.02 rad. Table 4 also shows that all specimens have rotation levels more than 0.03 radians, which is equal to the AISC minimum connection capacity for special moment frames. However, since the beam moment capacity exceeds the connection one in the flush end-plate and isolated connections, the deformation is concentrated within the connection components.

\subsection{Eurocode 3 Part 1-8 Classification Index}

The Eurocode classification requires the calculation of the initial rotational stiffness $\left(S_{j, \text { ini }}\right)$, where $S_{j, \text { ini }}$ contains the components' flexibilities $\left(K_{i}\right)$. $S_{j, \text { ini }}$ has to be compared with the beam stiffness defined as $\frac{E I_{b}}{L_{b}}$. Table 5 shows the initial rotational stiffness $\left(S_{j, i n i}\right)$ and connected beam stiffness for all three beam-to-column connections. According to Table 5 , the SidePlate is categorized as a fully-rigid connection, as its initial stiffness, $S_{j, \text { ini }}$, is higher than 25 times the connected beam stiffness, $\frac{E I_{b}}{L_{b}}$. Meanwhile the flush end-plate is to be considered as a semi-rigid connection, as its initial stiffness is higher than 0.5 times its connected beam stiffness. The isolated connection experienced high rotation during the test and therefore its initial stiffness is negligible compared to the other two types of connection. Similar to the AISC classification, the Eurocode also categorizes this connection as a flexible beam-to-column connection based on its stiffness.

Table 5. Connection assessment based on Eurocode classification

\begin{tabular}{|c|c|c|}
\hline $\begin{array}{c}S_{j, \text { ini }} \\
\left(\frac{k N . m}{\text { radian }} \times 10^{3}\right)\end{array}$ & $\begin{array}{c}\frac{E I_{b}}{L_{b}} \\
\left(\frac{k N . m}{\text { radian }} \times 10^{3}\right)\end{array}$ & Specimen \\
\hline 4.0 & 2.7 & Flush end-plate \\
\hline 68.1 & 2.7 & SidePlate \\
\hline 0.95 & 2.7 & Isolated \\
\hline
\end{tabular}

\subsection{Beam Reference Length Concept Classification}

The reference length concept is set up to correlate the connection stiffness. Based on evaluations of a variety of test data of beam-to-column connections, as presented by [28], it was noticed that a value of the reference length $l_{e}$ of five times the beam depth $d$, that is part of the connection, would be the most suitable for semi-rigid connections. Experimental results of different beam-to-column connections (Table 6) show the ultimate moments and equivalent reference lengths. The data in Table 6 confirm that the shorter is the equivalent reference length of the beam, the stiffer the connection will be. In other words, for the beam's initial stiffness to match that of the connection, a smaller length is needed for the stiffer connections.

To determine the dividing lines between semi-rigid and rigid and between flexible and semi-rigid, reference lengths of $10 d$ and $2 d$ are suggested. These values are proposed according to the equivalent length concept data that are shown in Table 6. Moreover, the information in Table 6 indicates that it will be accurate to consider a moment resistance of $0.7 M_{p}$ and $0.2 M_{P}$ for the semi-rigid to rigid and the flexible to semi-rigid connection resistance limits, respectively. For fully-rigid connections, it might be suitable to assume that the ultimate moment resistance is higher than $0.7 M_{P}$, or maybe even larger than the full plastic moment, $M_{p}$. This last value aims at ensuring that the failure mode occurs away from the connection components. Figure 11 shows the beam-tocolumn connection classification based on the beam reference length concept, where:

$$
\begin{gathered}
\Phi=\frac{\varnothing_{u}}{\varnothing_{p}}=\frac{\varnothing_{u}}{\left(\frac{M_{p}}{\left[\frac{E I}{5 d}\right]}\right)} \\
\dot{M}=\frac{M_{n}}{M_{p}}
\end{gathered}
$$

and $d$ is the depth of the connected beam.

Table 6. Equivalent length concept data for different beam-to-column connections [33]

\begin{tabular}{|c|c|c|c|c|c|}
\hline \multirow{2}{*}{ Description } & Rigid & \multicolumn{2}{|c|}{ Semi-rigid } & \multicolumn{2}{|c|}{ Flexible } \\
\cline { 2 - 6 } & Extended end-plate & Flush end-plate & $\begin{array}{c}\text { Top/seat angles, } \\
\text { web angles }\end{array}$ & Header plate & Double web angles \\
\hline Connection equivalent length $l_{e}$ & $1 d<l_{e}<2 d$ & $2 d<l_{e}<5 d$ & $4 d<l_{e}<7 d$ & $\approx 10 d$ & $\approx 15 d$ \\
\hline Connection ultimate moment $M_{n}$ & $\approx 0.9 M_{p}$ & $\approx 0.6 M_{p}$ & $0.45-0.6 M_{p}$ & $\approx 0.2 M_{p}$ & $\approx 0.15 M_{p}$ \\
\hline
\end{tabular}




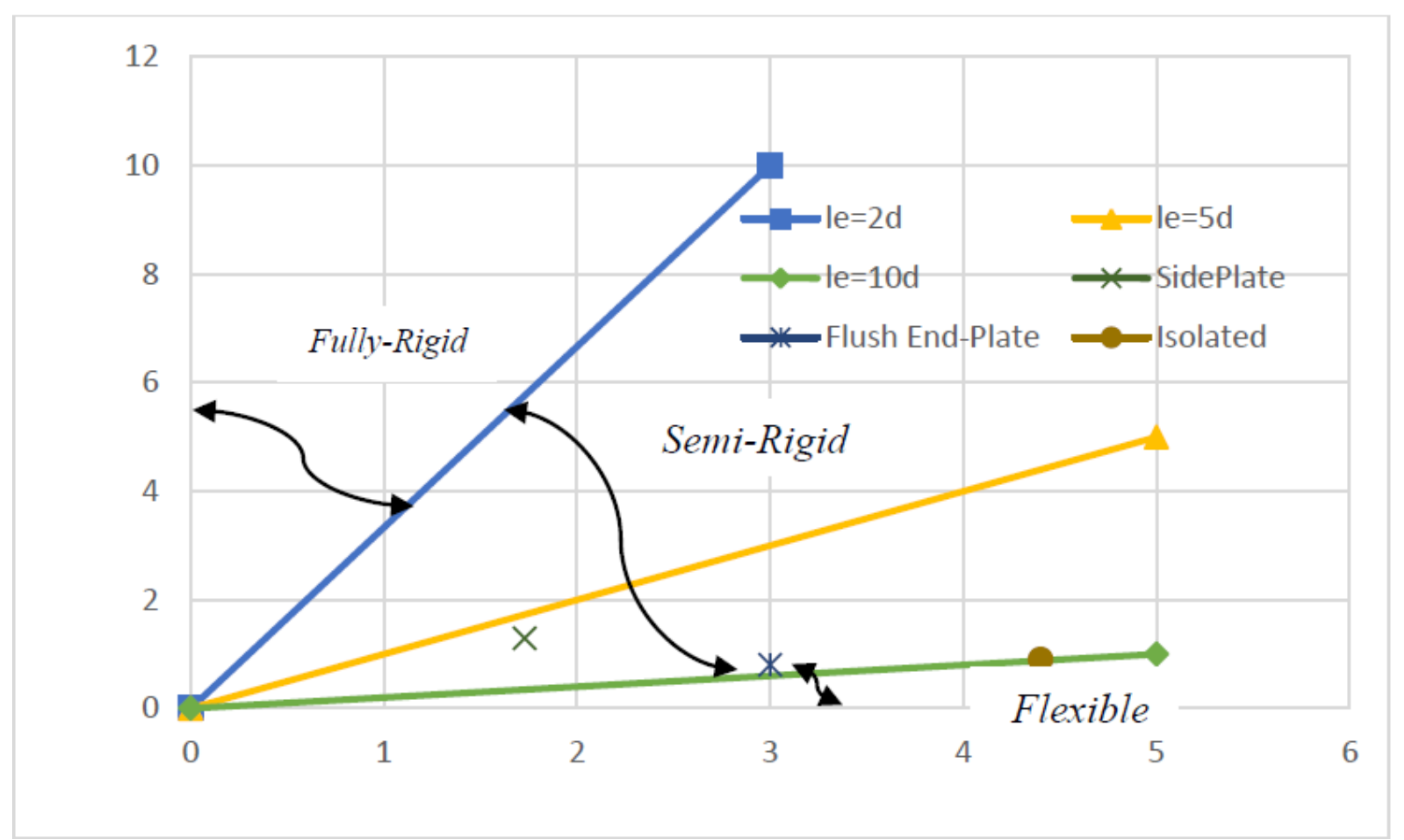

Figure 11. Beam-to-column connection classification based on beam reference length concept

Figure 11 shows that the beam reference length concept provides a conservative classification, where all three types of connection are categorized as semi-rigid. However, it indicates that the isolated connection possesses much more rotation capacity than the two other connections.

\subsection{Connection Qualification}

The drift angle capacity is considered as the fundamental quantity to evaluate a connection's performance, as shown in Figure 12. To calculation the $\theta$ shown in Figure 12, it is supposed that the bottom and top of the column are restrained against lateral movement.

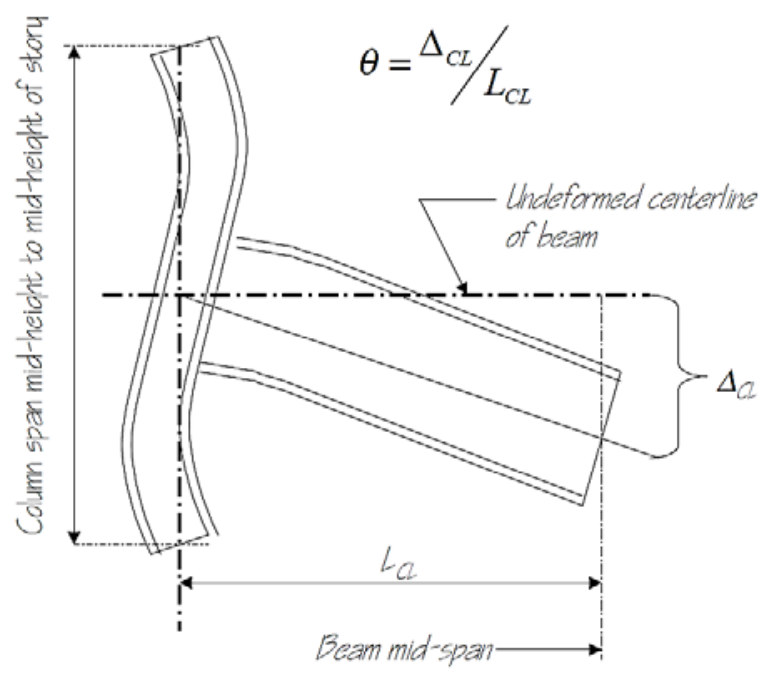

Figure 12. Description of drift angle

The value of $\theta$ at which the strength of the connection degrades to less than the nominal plastic capacity, $\theta_{S D}$, and the value of $\theta$ at which the connection damage is so severe that the continued ability to remain stable under gravity loading is uncertain, $\theta_{U}$, should be measured during the test. These values shall not be less than indicated in Table 7 based on the AISC regulation. Table 7 shows that both the SidePlate and isolated connection did address the drift angle capacity requirement of $\theta_{S D}$ for the special moment frame (SMF). Moreover, the isolated connection provided adequate drift angle capacity and reached 0.08 rad before severe damage in the top cover plate, which is $33 \%$ higher than the acceptance criteria for the special moment frame (SMF).

Table 7. Qualifying Drift Angle and Connection Drift Angle Capacity

\begin{tabular}{|c|c|c|}
\hline \multicolumn{3}{|c|}{ Qualifying Drift Angle Based on AISC } \\
\hline $\begin{array}{c}\text { Structural system/ } \\
\text { connection type }\end{array}$ & $\begin{array}{c}\text { Strength degradation, } \\
\theta_{S D} \text { (radians) }\end{array}$ & $\begin{array}{c}\text { Ultimate capacity, } \\
\theta_{U} \text { (radians) }\end{array}$ \\
\hline OMF & 0.02 & 0.03 \\
\hline SMF & 0.04 & 0.06 \\
\hline \multicolumn{2}{|c|}{ Connection Drift Angle Capacity } \\
\hline Flush end-plate & 0.02 & 0.06 \\
\hline SidePlate & 0.045 & 0.05 \\
\hline Isolated & 0.045 & 0.08 \\
\hline
\end{tabular}

\section{Concluding Remarks}

This paper investigated the structural performance of a new proposed steel beam-to-column connection retrofitted by elastomeric isolators. It evaluated its strength, stiffness and ductility, and compared these to SidePlate and flush end-plate beam-to-column connections. The ANSI/AISC 360-10 and Eurocode 3 Part 1-8 specifications were considered to determine the connection classification index. The drift angle capacity was also contemplated to identify the connection qualification based on AISC. The following conclusions have been made regarding the experimental and analytical results: 
i. Both the Eurocode and AISC classified the new proposed connection as a flexible connection based on its stiffness. The elastomeric isolators mounted in the connection led to high rotation during the test compared to the SidePlate and flush end-plate, which seriously affected the initial stiffness.

ii. Both the Eurocode and AISC classified the new proposed connection as a semi-rigid connection based on its strength. The new proposed connection developed the moment capacity of the connected beam up to $90 \%$ of the plastic moment.

iii. The strain gauge records showed that the column shear panel zone in both the SidePlate and the proposed connections remained intact after the final stage of the test.

iv. The effects of joint flexibility should be addressed in the analysis of the isolated connection and consequently the internal forces and bending moment diagrams constructed under the assumption of rigid joints contain considerable errors.

\section{Acknowledgements}

The authors wish to thank the esteemed technical staff of the Structures and Materials Laboratory, Universiti Teknologi Malaysia (UTM), for their cooperation and support in this study. Financial support provided by the Universiti Teknologi Malaysia Construction Research Centre (CRC) from grant number 4B235 for conducting the experimental work was invaluable, and the authors remain obliged.

\section{Nomenclature}

$\begin{array}{ll}B \text { or } L & \text { length of isolator } \\ t_{t} & \text { overall thickness of isolator } \\ t_{r} & \text { thickness of rubber layers } \\ N & \text { number of rubber layers } \\ t_{s} & \text { thickness of steel laminates } \\ \gamma_{\text {max }} & \text { maximum shear relative displacement capacity } \\ & \text { of rubber }(1 \approx 1.5) \\ G & \text { shear modulus of rubber }(0.69 \approx 0.86 \mathrm{MPa}) \\ \sigma_{c} & \text { allowable stress of isolator }(6.9 \approx 7.84 \mathrm{MPa}) \\ E & \text { rubber modulus of elasticity }(1.5 \approx 5 \mathrm{MPa}) \\ K_{v} & \text { vertical stiffness of isolator } \\ K_{h} & \text { horizontal stiffness of isolator } \\ E_{c} & \text { compression modulus of rubber and metal } \\ K & \text { laminates combination } \\ S & \text { modification factor }(1 \approx 1.5) \\ A & \text { configuration factor } \\ t_{i}, t_{i+1} & \text { required isolator area } \\ & \text { thickness of rubber layer top and bottom of } \\ f_{y} & \text { yield stress of metal laminates } \\ R & \text { behaviour factor of isolated structure }\end{array}$

\section{References}

[1] Miller, D.K., Lessons learned from the Northridge earthquake. Engineering structures, 1998. 20(4-6): p. 249-260.
[2] Nakashima, M., K. Inoue, and M. Tada, Classification of damage to steel buildings observed in the 1995 Hyogoken-Nanbu earthquake. Engineering Structures, 1998. 20(4-6): p. 271-281.

[3] Kartal, M., et al., Effects of semi-rigid connection on structural responses. Electronic journal of structural Engineering, 2010. 10(10): p. 22-35.

[4] Valipour, H.R. and M.A. Bradford, Nonlinear P-A analysis of steel frames with semi-rigid connections. Steel and Composite Structures, 2013. 14(1): p. 1-20.

[5] Aksoylar, N.D., A.S. Elnashai, and H. Mahmoud, The design and seismic performance of low-rise long-span frames with semi-rigid connections. Journal of Constructional Steel Research, 2011. 67(1) p. 114-126.

[6] Malley, J.O., SAC Steel Project: Summary of Phase 1 testing investigation results. Engineering structures, 1998. 20(4-6): p. 300-309.

[7] Roeder, C.W. and D.A. Foutch, Experimental results for seismic resistant steel moment frame connections. Journal of Structural Engineering, 1996. 122(6): p. 581-588.

[8] Hamburger, R.O. Prequalified Connections for Special and Intermediate Steel Moment Frames for Seismic Applications, ANSI/AISC 358-05. in Structures Congress 2006: Structural Engineering and Public Safety. 2006.

[9] Venture, S.J. and G.D. Committee, Recommended seismic evaluation and upgrade criteria for existing welded steel momentframe buildings. 2000: Federal Emergency Management Agency.

[10] Agency, F.E.M., Recommended seismic design criteria for new steel moment frame buildings. 2000, FEMA-350, SAC Joint Venture Washington, DC.

[11] Chen, C.-C. and C.-C. Lin, Seismic performance of steel beam-tocolumn moment connections with tapered beam flanges. Engineering Structures, 2013. 48: p. 588-601.

[12] Saffari, H., A. Hedayat, and M.P. Nejad, Post-Northridge connections with slit dampers to enhance strength and ductility. Journal of Constructional Steel Research, 2013. 80: p. 138-152.

[13] Latour, M., V. Piluso, and G. Rizzano, Cyclic modeling of bolted beam-to-column connections: component approach. Journal of Earthquake Engineering, 2011. 15(4): p. 537-563.

[14] Chou, C.C., et al., Seismic rehabilitation performance of steel side plate moment connections. Earthquake Engineering \& Structural Dynamics, 2010. 39(1): p. 23-44.

[15] WANG, Y., et al., Experimental study on beam-to-column connections with beam-end horizontal haunch of steel frame under low cyclic loading [J]. Journal of Building Structures, 2010. 4: p. 013.

[16] Aristizabal-Ochoa, J.D., Slope-deflection equations for stability and second-order analysis of Timoshenho beam-column structures with semi-rigid connections. Engineering Structures, 2008. 30(9): p. 2517-2527.

[17] Aristizabal-Ochoa, J.D., First-and second-order stiffness matrices and load vector of beam-columns with semirigid connections. Journal of Structural Engineering, 1997. 123(5): p. 669-678.

[18] Chen, W.-F., Y. Goto, and J.R. Liew, Stability design of semi-rigid frames. Vol. 1. 1996: John Wiley \& Sons.

[19] Committee, A., Specification for Structural Steel Buildings (ANSI/AISC 360-10). American Institute of Steel Construction, Chicago-Illinois, 2010.

[20] Hsieh, S.-H. and G. Deierlein, Nonlinear analysis of threedimensional steel frames with semi-rigid connections. Computers \& structures, 1991. 41(5): p. 995-1009.

[21] BS EN, B., Eurocode 3: Design of steel structures-Part 1-8: Design of joints. BS EN 1993-1, 2005. 8.

[22] Latour, M., V. Piluso, and G. Rizzano, Experimental behaviour of friction T-stub beam-to-column joints under cyclic loads. Steel Construction, 2013. 6(1): p. 11-18.

[23] Gasparini, D.A., A. DebChaudhury, and L.W. Curry, Damping of frames with viscoelastic infill panels. Journal of the Structural Division, 1981. 107(5): p. 889-905.

[24] Ocel, J., et al., Steel beam-column connections using shape memory alloys. Journal of Structural engineering, 2004. 130(5): p. 732-740.

[25] UBC, U.B.C. Uniform building code. in Int. Conf. Building Officials. 1997.

[26] Pan, P., et al., Base-isolation design practice in Japan: introduction to the post-Kobe approach. Journal of Earthquake Engineering, 2005. 9(01): p. 147-171. 
[27] Theocaris, P. and E. Marketos, Elastic-plastic analysis of perforated thin strips of a strain-hardening material. Journal of the Mechanics and Physics of Solids, 1964. 12(6): p. 377-380.
[28] Kishi, N. and W.-F. Chen, Data base of steel beam-to-column connections. 1986: Structural Engineering Area, School of Civil Engineering, Purdue University. 